\title{
Nanoparticle Effect on Interaction of Epirubicin with DNA ${ }^{\dagger}$
}

\author{
Leyla Karadurmus ${ }^{1, *}$, Sevinc Kurbanoglu ${ }^{1}$, Afzal Shah ${ }^{2}$ and Sibel A. Ozkan ${ }^{1}$ \\ 1 Department of Analytical Chemistry, Faculty of Pharmacy, Ankara University, Ankara 06100, Turkey; \\ skurbanoglu@gmail.com (S.K.); ozkan@pharmacy.ankara.edu.tr (S.A.O.) \\ 2 Department of Chemistry, Quaid-i-Azam University, Islamabad 45320, Pakistan; afzals_qau@yahoo.com \\ * Correpondence: leylakrdrms@gmail.com \\ + Presented at the 5th International Symposium on Sensor Science (I3S 2017), Barcelona, Spain, \\ 27-29 September 2017.
}

Published: 29 November 2017

Epirubicin, (7S,9S)-7-[(2R,4S,5R,6S)-4-amino-5-hydroxy-6-methyloxan-2-yl]oxy-6,9,11-trihydroxy-9(2-hydroxyacetyl)-4-methoxy-8,10-dihydro-7H-tetracene-5,12-dione, which is an antineoplastic in the anthracycline class, is a $4^{\prime}$-epi-isomer of the anthracycline antineoplastic doxorubicin. It is a topoisomerase inhibitor which inhibits topoisomerase II and intercalates into DNA, thus inhibiting DNA replication and ultimately, interfering with RNA and protein synthesis. Epirubicin is limited because of dosedependent side effects including cardio toxicity, bone suppression, low blood counts, hair loss, nausea and vomiting. Drug-DNA interaction studies can give us brief information on the journey of the drug in the human body. In this study, an electrochemical DNA-based biosensor was developed for the detection of DNA-Epirubicin interaction through the electroactive properties of guanine and adenine nucleotides. Initially, interaction time and concentration of Epirubicin in response to guanine were optimized. Moreover, nanoparticles were used to modify the screen-printed electrodes surface to enhance the electrochemical signal. The effect of silver nanoparticles (AgNPs) and platinum nanoparticles (PtNPs) was further studied in detail. Layer-by-layer modification of the screen-printed electrode-based DNA biosensor gave the highest guanine response and resulted in a well-followed decrease in guanine signal after interaction with $0.5 \mathrm{ppm}$ Epirubicin. With $5 \mathrm{~min}$ interaction time, the $\mathrm{SPE} / \mathrm{PtNPs} / \mathrm{AgNPs} / \mathrm{AgNPs}$ DNA biosensor gave a linear response between 0.1 and $1 \mathrm{ppm}$ Epirubicin.

(C) 2017 by the authors. Licensee MDPI, Basel, Switzerland. This article is an open access article distributed under the terms and conditions of the Creative Commons Attribution (CC BY) license (http://creativecommons.org/licenses/by/4.0/). 